\title{
The Numerical Simulation of the Green Residential Environment
}

\author{
Yangluxi $\mathrm{Li}^{*}$ \\ School of Architecture, Syracuse University, NY, USA \\ ${ }^{*}$ Corresponding author
}

\begin{abstract}
This paper is based on the research of the wind environment in a residential area. Comprehensive analysis of the residential building group's outdoor wind environment with two different layouts was made by using the establishment of the physical and mathematical models of the outdoor wind environments, and the application of professional CFD software Fluent Airpak for scientific research. Studies have shown that using a numerical simulation method to evaluate the wind environment of residential area has a significant role in assisting with effective design. It also has an important impact on the improvement of buildings' layouts to better the outdoor wind environment.
\end{abstract}

Keywords-residential groups; ranks layout; wind environment; energy-saving; numerical simulation

\section{INTRODUCTION}

With the increase of the continuous construction of the urban high-rise construction, the wind environment problems effecting residents have become increasingly prominent, and the focus of communities concern and attention. Building wind environment is the flow condition of the air on the buildings inside and outside space, as well as its impact on building [1]. In recent years, wind environment has gradually become an important part of the design for a building. The pros and cons of wind environment directly affect the health and safety of residents. If not addressed properly, it will cause adverse consequences. Through scientifically reached layouts of residential building groups, the rational organization of the natural ventilation makes the greatest impact of integration on the buildings and natural environment. It also allows residential buildings to obtain as much lighting and ventilation as possible, while preventing unnecessary energy loss for a better quality of life for the residents. In the planning of the building groups, the determinant most widely used from complex building arrangement is a layout with strip-unit dwellings, or townhouse apartments, arranged in low orientation with reasonable spacing. This arrangement can allow for each house to receive good sunshine and ventilation, as well as facilitate the arrangement of roads, pipe networks, and industrialized construction [2].

With consideration of the outdoor airflow and the residential building's plan and design, it becomes important to research methods for residential building energy efficiency and sustainability. Using residential group's numerical simulation details the outdoor field velocity, temperature and the pollutant distribution can be acquired. It has far-reaching significance to improve the living environment [3]. This paper takes a property's wind environment as an example and uses comprehensive analysis of the two kinds of row layouts' outdoor wind environment conditions to analyze. Through the establishment of the outdoor wind environment's physical and mathematical models, the application of professional CFD software, Fluent and Airpak can facilitate the scientific research. Research has shown that the method of using numerical wind tunnel simulation to evaluate the residential estate's wind environment has had a significant and important role for improving outdoor wind environment.

\section{NUMERICAL SIMULATIONS}

Numerical simulation of fluid flow signifies airflow governed by the fluid dynamics equations discretized and solved by the computer. The computer graphics are used to express the results visually. This kind of numerical simulation technique is called computational fluid dynamics CFD Technology [4]. In the past, this technology has been widely used in the manufacturing industry. In recent years, CFD technology is being used more in the building environment's simulation research. Although it has not yet been a universal application, it has made great development.

This paper analyses CFD with the Fluent software. Fluent Airpak software is a professional, artificial, environment system analysis software for engineers, architects, and designers. It can accurately simulate the physical phenomena of airflow, heat transfer and pollution in the research object, and according to the ISO 7730 standard it offers the technical indicators of measuring indoor air quality (IAQ), such as the comfort level, PMV, PPD, and so forth.

\section{A. Equations for Calculating and the Selection of Mathematical Models}

The turbulence model is a major component of CFD software simulation. The wind flow within the residential area is generally incompressible and low-speed turbulence, but its wind environment simulation is the numerical simulation of bluff body spoilers flow field [5]. The standard K- $\varepsilon$ model is a common mathematical model. The limit flow is formed with airflow and building contraction. The standard K- $\varepsilon$ model better effects the simulation of the limit flow, which is the wall constraint, with low computational cost, small waves and high precision in the numerical calculation. It is widely use in lowspeed turbulence and easy for network adaptation [6]. The basic control equations including quality and momentum 
conservation equations are used in this paper. If only considering steady-state effect, it is an introduction to the standard RNG K- $\varepsilon$ turbulence model for numerical simulation.

\section{B. The Set of Computational Domain and Boundary Conditions}

Before doing the numerical simulation of wind environment, we must establish an effective computational domain first. Reasonable determination of computational domain has an important impact on the results of numerical simulation. Too large computational domain will increase the number of grids, the workload and work hours, and will be a waste of resources. Too small of a computational domain will make the calculation results biased, and impact the accuracy of the simulation. After repeated scientific research, the scope was determined to be the calculation region is $300 \mathrm{~m} \times 200 \mathrm{~m} \times$ $100 \mathrm{~m}$.

After the determination of computational domain, the determination of the reasonable boundary conditions makes the simulation comparable to the real situation. Determining the wind direction and wind velocity by the analysis of the wind velocity and wind direction of the location, in this case, was done through the input conditions of the simulation region. In the calculation of this paper, the inlet was defined as the velocity boundary condition. Assume that the flow of the surface has been fully developed and has been restored to the normal flow without the blocking of the buildings, namely the outlet pressure is the atmospheric pressure. The surfaces of buildings and the ground are fixed, so the no-slip wall condition is used. Since the selected computational domain is larger, the airflow of the surface on the top and on the side is not affected by the building, so it is set as the free slip surface [7].

During the simulation analysis, grid generation quality has a great influence on the accuracy and stability of the results. The strength of the grid generation capacity is also an important factor to measure the performance of CFD generalpurpose software [8]. When using Airpak to do the simulation in this research, the unstructured grid technology is used. It includes a variety of shapes for meshing, which will maximize the presentation of the complicated underlying surface shape and improve the model simulation effects. The topological structure and boundary shape of the solving domain do not limit the unstructured grids. It is very easy to construct and will help generate the adaptive grid, which will automatically adjust the grid density according to the characteristics of the flow field. It is beneficial to improve the calculation accuracy of the local domain [9].

\section{MODELING AND THE SET OF ENVIRONMENTAL CONDITIONS}

\section{A. The Residential Group Model}

This paper looks at the simulation of the wind environment of two basic residential groups' layouts. Both of the two residential groups are plate structure and determinant layout. The sizes of all the buildings are the same and arranged from the South to North. The layout of the Group A consists of 9 buildings that are parallel to each other. All the buildings are 11 floors that measure 3 meters, totaling 33 meters high. Its layout is shown in Figure I. The layout of Group B is the alternating of front and back of 9 buildings. Three buildings to the South are 22 layers, each measuring 3 meters, and totaling 66 meters high Six of the buildings to the North are 17 layers, individually 3 meters as well, totaling 51 meters high. Its layout is shown in Figure II.

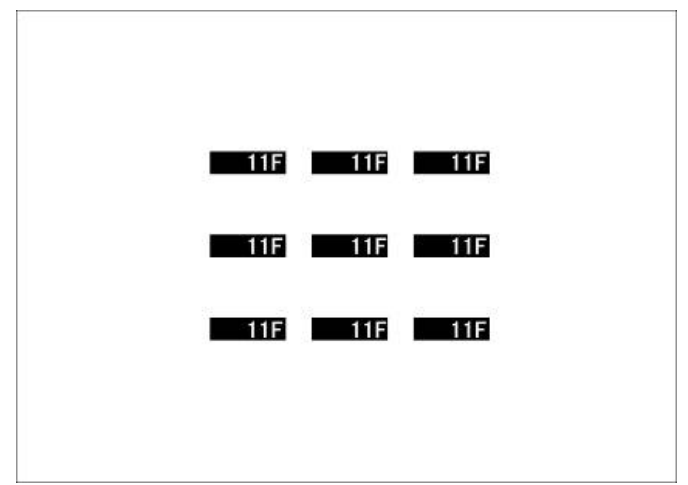

FIGURE I. LAYOUT OF GROUP A'S RESIDENTIAL BUILDING GROUPS

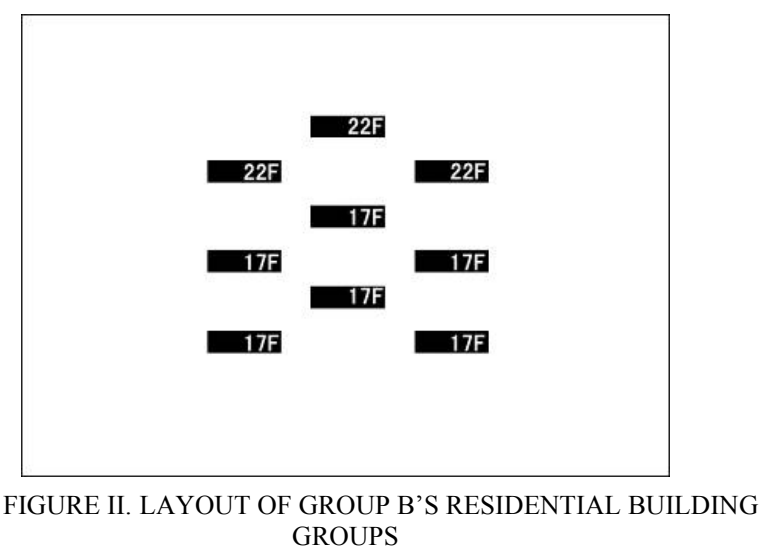

In order to facilitate the computational simulation and improve the calculation velocity, we use the similarity principle to idealized the building's shape as rectangular and simplify the actual model. The simulation models of Group A and B are built using this principle. For reference, Figure III is the simplified simulation model of Group A, and Figure IV is the simplified simulation model of Group B. The size of the model is proportional to the actual size and the plane simulation result used the measurement of $1.5 \mathrm{~m}$ to the ground. The plane wind environment was analyzed considering the pedestrian activity on the property. The main analysis of the modeling process is the buildings' inner wind environment. For this analysis, it is only necessary to consider the buildings' inner wind environment, so the wind environment around the structures will not be considered [10]. 


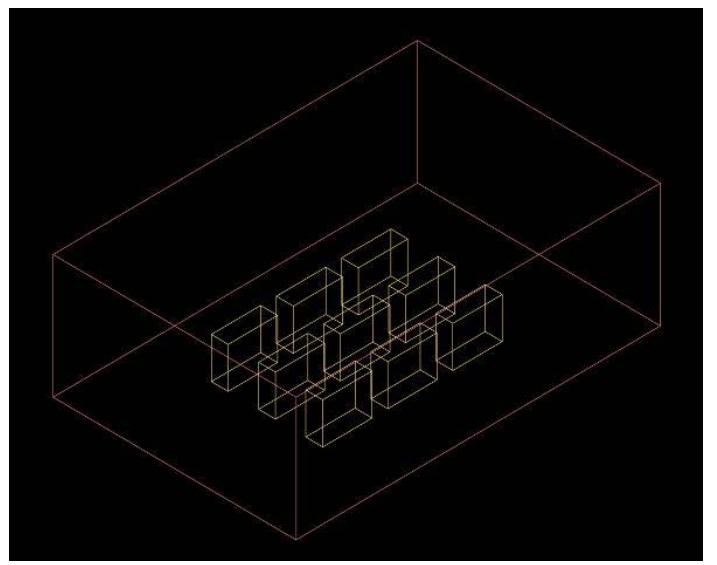

FIGURE III. SIMPLIFIED SIMULATION MODEL OF GROUP A

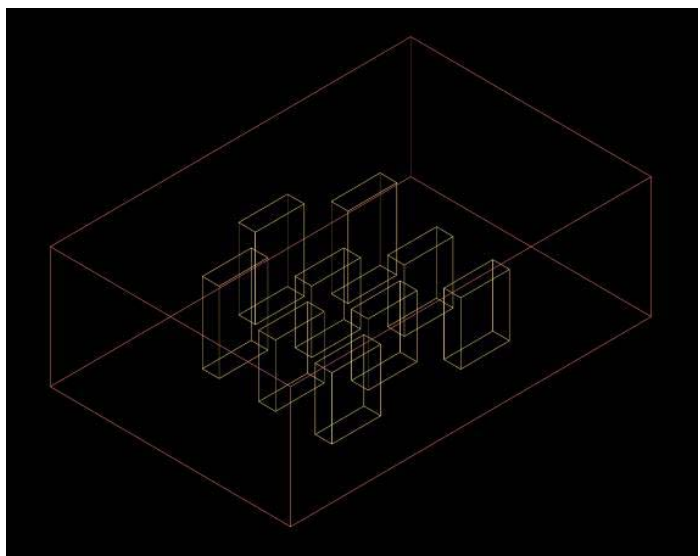

FIGURE IV. SIMPLIFIED SIMULATION MODEL OF GROUP B

\section{B. The Set of Environmental Conditions}

The dimensions of the model fully correspond to local regulatory requirements and meet the daily light and sunlight needs. With this reasonable factor, we consider that the only perennial dominant wind direction in the area is Southeast wind. It has an annual average wind velocity is $3.3 \mathrm{~m} / \mathrm{s}$, as the parameter of environmental climatic conditions in simulation analysis [11].

\section{THE ANALYSIS OF SIMULATION RESULTS}

Currently, the building codes of both domestic and international do not have a uniform standard of how to evaluate the pros and cons of the wind environment. The wind environment mainly affects humans. The pros and cons of pedestrian level wind environment directly impact the user's experience. Research on the conditions of pedestrian height wind environment, as the evaluation criteria of wind environment has become the interest of many different designers, architects and engineers. This paper analyzed the conditions of $1.5 \mathrm{~m}$, pedestrian height wind environment.

\section{A. The Simulation Results and Analysis of Group A}

It can be seen that from Figure $\mathrm{V}$, the maximum value of wind velocity is about $3.38 \mathrm{~m} / \mathrm{s}$, in the direction of East to West, and the wind velocity in the building groups generally decreases from Southeast to Northwest. As can be seen from Figure VI, the building groups' wind direction is roughly from East to West. This is because the distance between buildings from East to West is small, which blocks the movement of airflow. As can be seen from the wind velocity vectogram, the leeward side of residential buildings forms an eddy current phenomenon. However, the south side of the building forms a stronger airflow. This is because the front row of buildings blocks the airflow while it passes through the building groups.

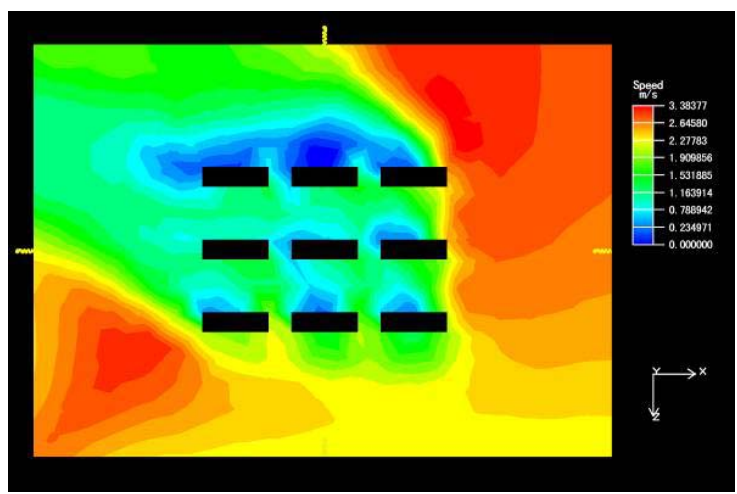

FIGURE V. WIND VELOCITY OF 1.5M HEIGHT SIMULATION OF GROUP A

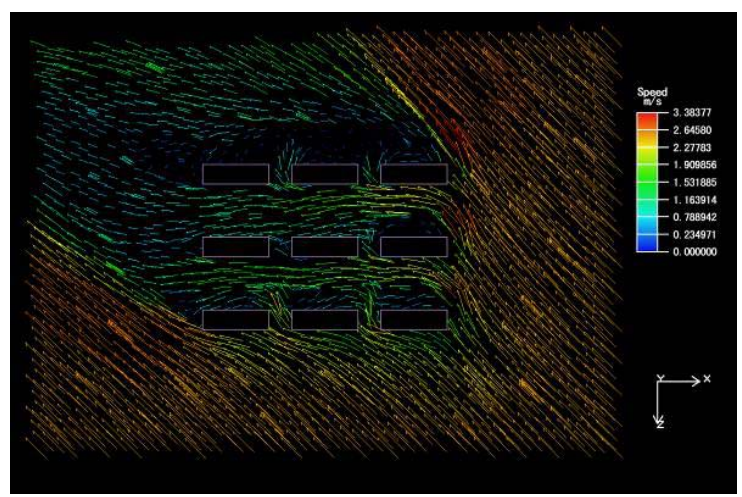

FIGURE VI. WIND VELOCITY OF 1.5M HEIGHT SIMULATION OF GROUP A

\section{B. The Simulation Results and Analysis of Group B}

As can be seen from Figure VII, under the same environment conditions with Group A, the results of simulation are different. First, buildings are in an East to West arrangement, but Group B used dislocation of the front and back layout, the inlet wind is Southeast wind, the wind velocity in building groups change little, and wind velocity decrement situation is very weak. As seen in Figure VIII, the building groups' Southeast wind inlet is almost the same as Group A. The wind velocity changes of Group B are even and very small, and without the leeward side vortex phenomenon and south side's strong wind phenomenon, as can be seen in Group A. It formed the East to West ventilated corridors with flat wind velocity [12]. Between the arrangement of the front and back buildings, the wind velocity changes unevenly, the wind velocity was either strong or weak, but the building groups' air distribution of Group B was even . 


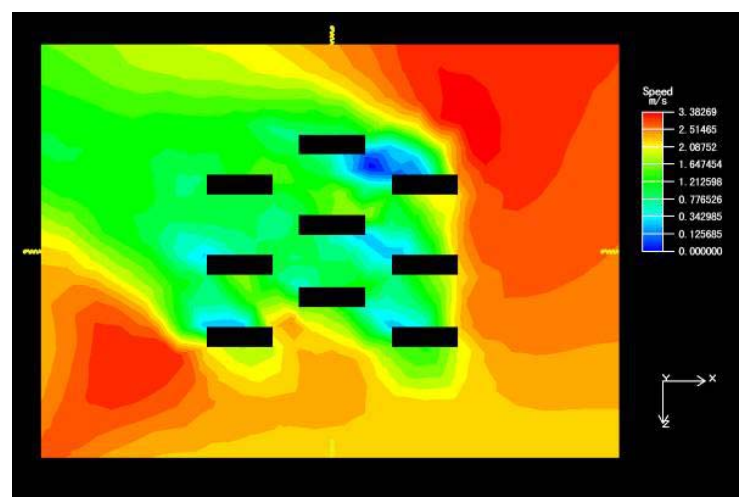

FIGURE VII. SIMULATION OF WIND VELOCITY UNDER PERENNIAL DOMINANT WIND WITH 1.5M HEIGHT OF GROUP B

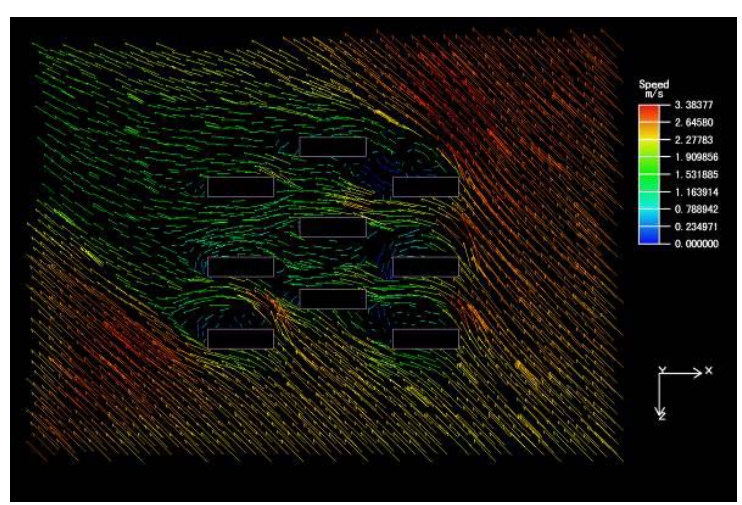

FIGURE VIII. SIMULATION OF WIND VELOCITY UNDER PERENNIAL DOMINANT WIND WITH 1.5M HEIGHT OF GROUP B

\section{CONCLUSIONS}

According to the wind environment simulation results of the two residential building groups, it can be seen that when the buildings are in a parallel arrangement like Group A, the wind velocity is increased at the entrance of the residential groups but the magnitude is not. Due to the blocking of wind by the front row buildings, the airflow around the back row of buildings is gradually weakened. This may have adverse effects on natural ventilation and stagnate pollutant. When the buildings' layout is arranged alternating front and back such as Group B, the wind velocity in the complex channel of building groups changes to smooth and constant. The amplitude is also decreased due to the layout. Wind velocity in each direction, due to the blocking, made the Northeast inlet have a smooth flow from the East to West, allowed for the normal smooth natural ventilation, and was good for the internal pollutants dispersion. This will not produce the adverse effects of poor ventilation and stagnate pollution. It is conducive to the normal activities and security of internal staff, and can guarantee them better comfort and health.

City wind environment has gradually become the key focus of city environment problems, and increased concern and attention of the community. The city's rapid development and urban residential expansion, especially the continuous construction of the high-rise complexes, have generated a series of environmental problems that cannot be ignored. Various professionals in the field have actively called attention to researching the environmental problems of the residential building groups. This issue is closely linked with urban residents' quality of life and the health. This article further states this issue and uses the professional, scientific environment simulation software to do the numerical simulation of wind environment. Based on research, there is an influence on the conditions of the building groups' layout to residential estate's wind environment during the residential estate design. Through scientific means to designers are able to determine whether the planning and design are reasonable. This article provides a reasonable and scientific reference for planning and design, and provides some guidance for building a good environment of residential estate.

\section{ACKNOWLEDGMENT}

This work was financially supported by the national invention patents of ZL 201310080487.4 and ZL 20131 0080484.0

\section{REFERENCES}

[1] P. Gousseau, B. Blocken, T. Stathopoulos and G. J. F. Van Heijst, CFD simulation of near-field pollutant dispersion on a high-resolution grid: a case study by LES and RANS for a building group in downtown Montreal. Atmospheric Environment, 2011, 45(2), 428-438.

[2] Y. L. X. Li, The application of CFD software in architectural and planning, Advanced Science Letters, 2013, volume 19:1886-1890(5).

[3] L. E. Jackson, The relationship of urban design to human health and condition. Landscape and urban planning, 2003, 64(4), 191-200.

[4] Y. L. X. Li, Analysis of the Planning of Neighborhood Communication Space in the Livable Community, Applied Mechanics and Materials, Vols. 174-177, pp. 3018-3022, 2012.5.

[5] J. D. Anderson and J. Wendt, Computational fluid dynamics (Vol. 206). New York: McGraw-Hill, 1995.

[6] C. Kittas, T. Boulard and G. Papadakis, Natural ventilation of a greenhouse with ridge and side openings: sensitivity to temperature and wind effects. Transactions of the ASAE, 1997, 40(2), 415-425.

[7] S.Y. Yi, Optimizing the Effect of Indoor Ventilation by CFD Simulation Analysis. Urban Development, 2010(9).

[8] V. S. A. S. T. B. C. G. Yakhot, S. A. Orszag, S. Thangam, T. B. Gatski, and C. G. Speziale, Development of turbulence models for shear flows by a double expansion technique. Physics of Fluids A: Fluid Dynamics (1989-1993), 1992, 4(7), 1510-1520.

[9] L. M. Smith and S. L. Woodruff, Renormalization-group analysis of turbulence. Annual Review of Fluid Mechanics, 1998, 30(1), 275-310.

[10] A. Mistriotis, G. P. A. Bot, P. Picuno and G. Scarascia-Mugnozza, Analysis of the efficiency of greenhouse ventilation using computational fluid dynamics. Agricultural and Forest Meteorology, 1997, 85(3), 217 228.

[11] T. Boulard, R. Haxaire, M A. Lamrani et al. Characterization and modeling of the fluxes induced by natural ventilation in a greenhouse. Journal of Agricultural Engineering Research, 1999, 74:135-144.

[12] T. Boulard, R. Haxaire, M. A. Lamrani, J. C. Roy and A. Jaffrin, Characterization and modelling of the air fluxes induced by natural ventilation in a greenhouse. Journal of Agricultural Engineering Research, 1999, 74(2), 135-144. 